Ssciendo Studia Anglica Posnaniensia 54s1 (2019): 267-285

doi: 10.2478/stap-2019-0013

\title{
TO QUOTE OR NOT TO QUOTE: LITERARY QUOTATIONS AS CHANGE FROM ABOVE
}

\author{
DON CHAPMAN ${ }^{1}$
}

\begin{abstract}
Phrases deriving from literary quotations are sometimes included in language histories as contributions from famous writers, like Shakespeare. This paper will argue that the label "change from above" is still a useful label for the addition of literary phrases to the language, even if such an addition is not typical of the variationist changes for which the label was coined. This paper will also demonstrate that the process of incorporating a literary quotation into the language involves several alterations to the quotation's form and meaning, and that these changes are also part of the "change from above" characterizing the adoption of literary phrases.
\end{abstract}

Keywords: Literary quotations; prestigious variant; alterations; additions; social valuation; lexicon; quoting.

From time to time, popularized histories of the English language list phrases that have derived from famous authors, like "to be or not to be" or "a rose by any other name would smell as sweet". These histories assert that such phrases have somehow "entered" the English language. "Expressions we use today" is how Bragg (2003: 145) characterizes them; "entered the language and have become, in some cases, cliches" is how McCrum, Cran \& McNeil (1986: 103) describe the phenomenon, and Crystal (2004: 330) refers to it as sentences and phrases that have "become part of general English idiomatic expression". To be sure, this is a peripheral phenomenon, probably included in such histories more for the fame of the author than the importance of the construction. As such, it would seem like a good candidate to be labeled "change from above", and indeed this paper will examine the ways that the addition of literary phrases can be considered "change from above".

1 Don Chapman, 4064B JFSB, Brigham Young University, Provo, Utah 84602, USA, don_chapman@byu.edu 
At its most general conception, this change is an addition: phrases are added to the language, much as words are added to the lexicon. Quoted phrases can come from many sources, such as popular music, advertising, politics, movies, and folk proverbs, and Regier listed fifty-five different types of quotations before he said he reached diminishing returns (Regier 2010: 21-45). It is likely that these different types of quotations will share some similarities with literary quotations, but this paper examines only those phrases coming from literary works, like those phrases included in Crystal (2004: 330-331):

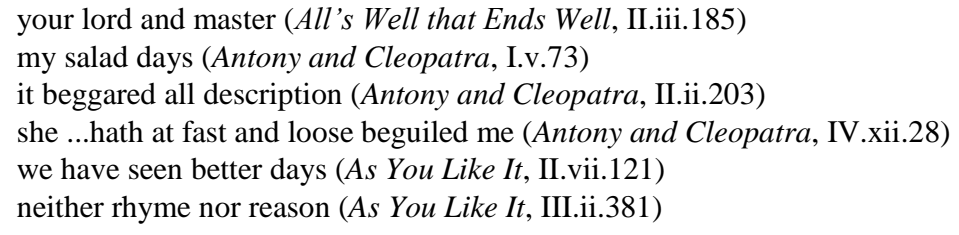

Since speakers from all walks of life regularly encounter and use phrases like "fast and loose", "seen better days", and "neither rhyme nor reason", these phrases indeed seem to have been added to the language.

From one perspective, labeling these additions as "change from above" should be relatively uncontroversial. The changes involve a high degree of conscious use (perhaps even more than lexical additions usually do), they move toward a prestigious variety of the language, they involve some formal learning, and they are sporadic and highly constrained by stylistic considerations. All these considerations have characterized "change from above" as formulated originally by William Labov and elaborated later by Labov and others. Labov's criteria for "change from above" originally focused on being sporadic and irregular, moving toward a prestige model, and being above the level of speaker awareness (Labov 1972: 178-179). Hawkey (2016), who examined the development of this term from Labov through such scholars as Wolfram \& Schilling-Estes (2005) and Romaine (2003), extracted three axes from the literature: 1) the change involves linguistic variables above speakers' and writers' consciousness, 2) the change tends toward overtly prestigious forms, and 3) the change involves some level of language planning. The addition of literary phrases seems to operate on the first axis (i.e., above the level of consciousness), as speakers and writers, at least initially, mean to incorporate the memorable phrases of others into their own language use. Speakers and writers often show explicit awareness of their quoting practice, by including quotation marks, quotatives, attribution, or other signs of quoting, as in the following examples: 


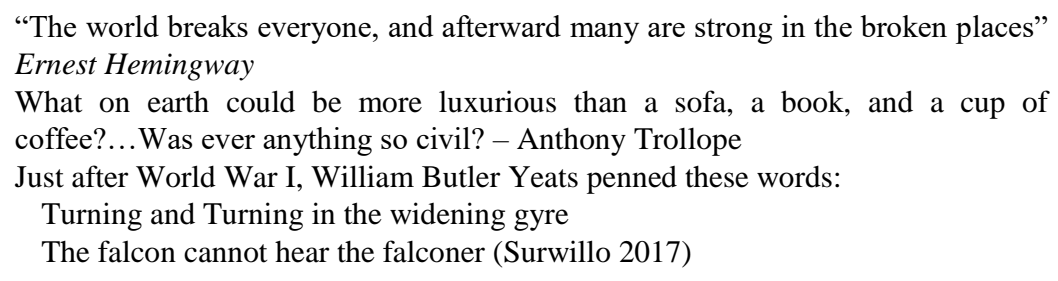

The addition of quotations would constitute change from above on the second axis (i.e., tends towards prestigious forms), as well, since the literary quotations link the speech or writing to literary writing, a variety of language with high cultural prestige. The third axis (i.e., involves language planning) may also be relevant, since the practice of literary quoting is often tied to classroom teaching, where the canonical authors are studied (Finnegan 2011: 33, 64). These changes depend on "external sources" and "the influence of learned registers" (Michael 2015: 492).

The addition of quoted phrases is also sporadic, irregular, and fragmentary. As D'Arcy and Tagliamonte observe about change from above,

It involves isolated features from outside the local speech community, and so may affect only parts of the linguistic system rather than sweeping through the language as a whole. This renders the outcome less predictable and less systematic than change from below (2015: 258)

Indeed, the adoption of literary quotations is highly unpredictable, unsystematic, and constrained by stylistic considerations. Literary quotations constitute a very small portion of the lexical stock. So on the surface, the addition of literary quotations to the expressive stock of English would seem to be precisely the kind of phenomenon that needs a label like "change from above" to separate it from other, more fundamental and systematic changes.

But there are some problems with using "change from above" for the addition of literary phrases to the language. The term "change from above" originated in variationist sociolinguistics, where it is still used to characterize variation in which speakers and writers are conscious of choosing prestigious variants. In such studies, the linguistic variables are generally structural, not lexical (Grieve, Nini \& Guo 2017: 100-101, 116-117), and since the variants theoretically all perform the same function, the choice of variants can index extra-linguistic factors (Tagliamonte 2012: 3-5). It is not clear that an addition to the lexicon functions the same way. As Robinson (2012: 38-39) notes, meaning is much fuzzier and harder to segment as a discrete variable. Durkin (2012: 6) adds that "in any situation [regarding the lexicon] where we want to measure variation, we cannot make any easy assumptions about what the available pool of variants will be". Moreover, words are polysemous, so that "beside Labov's classic definition of the sociolinguistic variable as showing two or more ways of saying one thing, 
we also have to consider that words can be one way of saying two or more different things" (Durkin 2012: 6). Clearly, "change from above" used in a technical sense peculiar to sociolinguistics does not fit as readily when describing the addition of even a word, let alone a phrase, to the lexicon.

Nevertheless, the core sense - that speakers are aware of the social valuation of their choice of variants - still makes "change from above" a useful term, and Hawkey explicitly provides for the possibility that "change from above" is not limited to "individual linguistic variables" (Hawkey 2016: 183). It may be difficult to formalize the choice of a particular literary quotation as one variant competing with others, but quoting literary works may be regarded as a prestigious discursive practice (Regier 2010: 99-101; Marmur 2014: 19), ${ }^{2}$ so it will still prove useful to analyze the change as motivated by prestige. If the term "change from above" can be extended to situations leading to language change in which the speakers and writers are conscious of the social valuation of their choices - even if the choices aren't among variants for structural variables - it will be a useful term for this kind of change.

The peripheral status of literary quotations makes their addition an interesting case of language change. For most language change, the new variant that eventually becomes established in the language starts out as a linguistic element, such as a phonetic or morphological variant. But quotations do not start out as linguistic elements on the same scale; they are written or spoken passages that others find worthy of copying for some reason. Quotations start out as a discursive practice, and their becoming linguistic elements constitutes the language change.

When a quotation is first used in a language, its connection to its source is crucial. That connection is presumably what attracts writers or speakers to the passages they extract from the original work. At first, writers and speakers mean to extract direct quotations that reproduce the passage from the original as accurately as possible and acknowledge the source, the author, and perhaps even the importance of the passage within its original context. These connections are illustrated in the following passage that quotes directly from Joyce's Portrait of the Artist as a Young Man:

it may be wondered whether this Old English "kin" is not to be opposed to the Irish "race" mentioned only a few lines later in the famous ending of the Portrait: "I go to encounter for the millionth time the reality of my experience and to forge in the smithy of my soul the uncreated conscience of my race" (Bénéjam 2005: 275-276).

2 Finnegan notes that quoting must be practiced skillfully to garner approval, however. Her respondents frequently connected quotations with pretentiousness as well as erudition (Finnegan 2011: 67). Nevertheless, either response points to the perceived prestige of quoting. 
In this example, quoting is used as a discursive practice, with no presumptions of adding to the lexical stock. The writer (Bénéjam) is quoting Joyce, because she is discussing Joyce's writings, and the full context of the quotation is important. The source and author are mentioned, the page is cited, the quotation is set off with quotation marks, and it is presented verbatim. All these features indicate a high level of consciousness in the use of direct quotations.

But at some point, a quotation becomes selected and sharpened, shortened and diffused to the point that it is felt less as a quotation and more as a phrase. When Crystal, McCrum, and Bragg single out Shakespeare in their histories of English, their point is not primarily that Shakespeare was a great writer who penned great literature that is worthy of quoting. Instead, their point is that in some way, some of these quotations - shortened and removed from their original context - have become part of a general repertoire that speakers can draw from, many times without even realizing there was a literary source for the phrase. At this point, the phrase looks like something we might term a linguistic element, similar to words, that are somehow part of the language.

The nature of that element may be hard to formalize, however. Such phrases are not words, but they show many similarities. Multi-word units, like these phrases, have attracted increasing scholarly attention, sometimes under the label of "formulaic language". Like words, formulaic language seems to be stored in some way. In an early paper investigating the nature of the lexicon, Charles Fillmore used the term phrasicon ${ }^{3}$ as some kind of repository for "expressions ... [that] have to be viewed both as lexical items and as entities having grammatical structure on a level higher than that of word-formation" (Fillmore 1978: 149). He included idioms, fixed phrases, clichés, and speech formulas among these expressions. De Cock et al. (1998) similarly used the term phrasicon to capture the notion that phrases are somehow stored, without committing to a model that requires them to be treated identically to words. Wray (2008: 9-21) makes a tighter connection, positing that 'morpheme equivalent units' (MEU) like phrases reside alongside words in a speaker's lexicon. In Wray's conception, phrases can overlap with words and the same phrase can be stored as a unit by some people, but analyzed into smaller parts by others. This results in two kinds of phrases in a lexicon: fixed phrases that are invariant, like kick the bucket (vs. *kick a bucket, *kick some buckets, *kick over the bucket) and partially fixed frames, which have some invariant and some variant portions, like "as __ as can be", where the slot is filled by some adjective fast, clever, or kind. As will be discussed later, both fixed phrases and partly-fixed frames are important derivations from literary quotations, and both seem to be established in the language.

3 The term phrasicon turns up at least as early as 1633 as a title of a sort of dictionary of Latin phrases (Huise 1633). 
The move from a direct quotation to a stock phrase is a crucial process that a quotation undergoes as it becomes established in the language. To understand that process better, I have searched the Corpus of Global Web-Based English (GloWbE) (Davies 2013). This corpus was chosen mainly because it comprises 1.9 billion words, which is large enough for a phenomenon as infrequently attested as literary quoting. The GloWbE corpus is composed of internet websites, which represent many different registers, including several informal registers. Over 500 quotations from 180 different authors were searched, using as search terms the smallest segment of the quotation that could yield a reliable match. These pieces typically needed to be small enough to catch non-verbatim quotations, and often searches for collocations instead of direct strings were performed. For example, two terms served to match Joyce's "Welcome, O life! I go to encounter for the millionth time the reality of experience and to forge in the smithy of my soul the uncreated conscience of my race." Both "uncreated conscience" and "smithy" collocating with "soul" are the types of phrases most likely to be quoted and most likely to identify Joyce's quotation. The following discussion of change from direct quotation to stock phrase derives largely from the results of these searches, as do most illustrative quotations.

The basic progression from a direct quotation to a stock phrase was outlined at least as early as 1858, when John Henry Newman added the contribution to daily speech as another reason to celebrate great writers:

He expresses what all feel, but all cannot say; and his sayings pass into proverbs among his people, and his phrases become household words and idioms of their daily speech, ... . (Newman 1976 [1858]: 244).

Here Newman outlines a progression from sayings to proverbs to household words and idioms in daily speech. Later scholars have noted this same progression. Knowles (2009: 15) writes

\footnotetext{
Quotations, like other linguistic items, may transmute, shift their ground, generate fixed phrases, or become clichés. The point is often reached at which we can say that the linguistic status of the item has changed, and it has become part of the wider vocabulary.
}

This progression essentially moves from greater consciousness of the literary origin of the phrase to less consciousness. For most of the stages, the key insight of change from above - that speakers are conscious of the social valuation of the variant (or discursive practice) they choose - is evident and important for the change. Yet at some point, that consciousness becomes greatly reduced, if not completely absent, for some phrases, like "thin air" and "one fell swoop". 
The important changes in this progression are those that increasingly separate the quotation from its original passage. One of the first stages is selection. From all the writing of all esteemed authors, discourse communities somehow have to select which passages they want to memorialize. Undoubtedly the use of direct quotations in prose, like the quotation from Joyce given above, is part of this process. Internet quoting practices bring out some other, more explicit mechanisms of selection, namely the compilation of quotations and use of quotations as signatures at the end of messages. Many internet sites provide a variety of quotations, like the following example, where a quotation from Oliver Goldsmith is lumped together with other famous, though non-literary, figures (Jajah 2012):

"As I grow older, I pay less attention to what men say. I just watch what they do." - Andrew Carnegie

"You can preach a better sermon with your life than with your lips."

— Oliver Goldsmith

"The finest eloquence is that which gets things done."

— David Lloyd George

"The actions of men are the best interpreters of their thoughts."

— John Locke

Similarly commenters or bloggers often include a quotation or two in their signature, as illustrated in the last line of a profile for a commenter on The Daily Kos:

nicolemm Joined in 2004

Community

$[\ldots]$

No one can make you feel inferior without your consent-Eleanor Roosevelt

(nicolemm 2018)

Most of these quotations maintain some connection to the original author, since the author provides some cachet, but the original work from which the quotation was taken is seldom listed, and the meaning of the quotation in context is usually effaced entirely.

As certain quotations are repeated more frequently than others, and as they are gathered into compendia including quotation dictionaries, they become more noticeable and thus more available for productive use. They also become decontextualized; when the quotation is simply listed with many other quotations or merely tagged onto an email, the allusions inherent in the quotations are diminished considerably, if not entirely. Such shedding of context may be an important early step for a quotation to be used productively.

Another important stage comes from writers and speakers adapting the wording of the quotation to their own purposes. In the corpus evidence, such adaptation is very common. Some adaptations are a matter of shoe-horning a 
quotation into the writer's own prose, such as changing a they to a we, or a present tense verb to a past tense verb. In the following example, the original quotation is "History, Stephen said, is a nightmare from which I am trying to awake" (Joyce 1961 [1922]: 34). The writer adapts the quotation by extracting the quotative "Stephen said" to make his own sentence smoother: "When Joyce's Stephen Dadalus said, 'History is a nightmare from which I am trying to awake,' he summed up Irish history" (Boorstin n.d.). Such shoe-horning separates the quotation, though slightly, from its original form.

Greater separation comes from shortening a quotation, and extensive shortening constitutes one of the most important stages toward becoming a stock phrase. The phrases said to have entered the language, like those listed in Crystal, have all been considerably shortened. When a quotation is reduced to a short phrase and separated from its original context, the phrase is available for a much wider variety of uses. Within the GloWbE searches, many of the most frequent phrases are just such short phrases like "a modest proposal", "scarlet letter", "yellow brick road", and "tea and sympathy".

The process presented so far has been fairly streamlined and linear: direct quotations are selected and then reduced and stripped of context until a fairly short phrase is available for a wide variety of contexts. As these short phrases are picked up and repeated by other speakers and writers, the phrases can be said to be part of the expressive repertoire. But the corpus record shows a much more varied and complex process. There are several more ways that quotations end up contributing to the lexicon, without going so far as to become stock phrases.

Occasionally a quotation remains fairly long and fairly literary-sounding, even after it loses its contextual information (i.e., original author, source text, original context). Two that stand out from the corpus searches are "live to fight another day" and "there but for the grace of God go I". The sentiment behind "live to fight another day" has a long history, variously attributed to Demothesenes, Menander, Samuel Butler, and others (Bent 1887). The present formulation seems to come from Oliver Goldsmith: ${ }^{4}$

\footnotetext{
He who fights and runs away

May live to fight another day;

But he who is in battle slain

Can never rise to fight again
}

The shortened form "live to fight another day" seems to fill a lexical gap of sorts, and is included in several on-line dictionaries. The Cambridge Advanced

\footnotetext{
This quatrain appears in Goldsmith (1761: 147) in a passage otherwise quoting Samuel Butler's Hudibras. It matches Butler's sentiments, but not his wording. Yet Goldsmith gives no indication that he is departing from Hudibras, nor does he take credit for the lines.
} 
Learner's Dictionary and Thesaurus is able to give a paraphrase, but offers no equivalent single terms: "to have another chance to fight in a competition; to be able to continue with your life although you have had a bad experience" (Cambridge Advanced Learners Dictionary and Thesaurus). Indeed, the phrase "live to fight another day" had the most occurrences $(251 \times$; search string: "live to * another day" performed on 20 July 2016) among the 500-plus corpus searches not including Shakespeare and the King James Bible.

The phrase "there but for the grace of God go I" is a similarly long phrase that seems to have entered the lexicon, occurring 56 times in the GloWbE corpus (search string: "grace of God go I" performed on 11 July 2016). It also has a questionable provenance, being customarily attributed to John Bradford as an apparent oral quotation (O'Toole 2014). This phrase has several literary qualities, such as the old-fashioned use of but, the inversion of the subject and verb, and the fronting of the adverbial "but for the grace of God". It usually shows up with quotation marks in the GloWbE corpus, signaling that writers still recognize it as a quotation. But it hardly ever bears attribution, showing that writers are less concerned for its original source and context.

Another important use of quotations is in formulas or templates, or what Wray calls "partly-fixed frames" (2008: 16). These are instances that keep a few words invariant, while allowing other words to vary. The quotation "live to fight another day," for example, has given rise to just such a frame when fight is varied with other verbs: "live to [sing, ski, dance, write] another day." Partly-fixed frames probably arise from processes akin to shoe-horning, in which writers adapt quotations to their own needs. In the following quotation, for example, the writer substitutes "the people of Northern Ireland are" for "I am":

\footnotetext{
But history is a nightmare from which the people of Northern Ireland are trying to awake and there was a definite air of reconciliation about yesterday's ceremony and its aftermath in the nearby Catholic church (De Breadun 2012; underlining added)
}

As more and more writers substitute different words within the same slot of a given situation, we may speak of a template or partly-fixed frame. Thus "the face that launched a thousand ships" can become "the video that launched a thousand snoods," "the image that launched a thousand therapists," or "the show that launched a thousand skinny ties". The degree that the frame remains connected to its literary source will vary. Sometimes writers will explicitly acknowledge the source (e.g., "As Jane Austen might have said..."), and sometimes the template is so complex that we suspect that the writer must have known the original, as in the extensive uses of Jane Austen's "It is a truth universally acknowledged". This is the most productive frame from the GloWbE searches, with 79 instances of writers adapting this quotation (search term: "truth universally acknowledged" 
performed on 13 July 2016). The basic template is "It is a truth universally acknowledged that", and in the slot, writers may put any piece of wisdom that they want to assert as readily accepted.

"It is a truth universally acknowledged that the first crepe is the practice one."
"It is a truth universally acknowledged that small boys are drawn to big castles."

A few uses of this frame go beyond the opening tag, using the entire first sentence as the template: "It is a truth universally acknowledged that a in possession of a must be in want of a ,

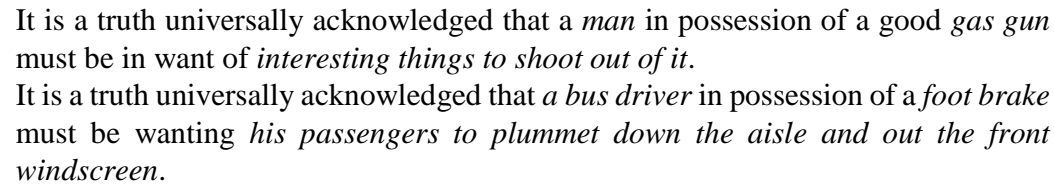

These template adaptations achieve their effect by maintaining a connection to the original formulation of the quotation and possibly the original author and source text. Partly-fixed frames are not the same as stock phrases, yet writers still use them productively. As with stock phrases, writers work them into their prose in new ways, but partly-fixed frames maintain a closer connection to their origin than stock phrases.

Perhaps the most common type of changes to quotations is inadvertent changes made as speakers and writers pass them along (Knowles 2009: 17). One example comes from Mercutio's lines in Romeo and Juliet: "I am hurt. / A plague a' both houses! I am sped" (3.1.90-91). Of the 120 occurrences of this phrase in GloWbE (search term: "a * on both" performed on 18 February 2019), writers use plague 31 times, pox 91 times, and curse once. Somehow plague has become pox for three quarters of the quotations. And a possessive determiner like their or your shows up on 115 of the 123 tokens. Only two keep the original $a^{\prime}$ that is recorded in the Riverside edition (with no hint of textual variation given in the critical apparatus). It is clear that changing quotations is a part of quoting.

Some changes seem to move towards a writer's more natural way of stating the phrase. For example, a quotation from Binyon reads "They shall grow not old as we that are left are old", yet of the twenty-nine tokens from GloWbE (search term: "we that are left" performed on 18 July 2016), six use "shall not grow" instead of "shall grow not" and another uses "shall never grow". It appears that writers sometimes convert the unusual or dated syntax to their own more natural syntax. In another case, writers have inserted their own preferred determiner instead of the poem's. The fuller quotation for "green and pleasant land" is "In England's green and pleasant land," but a plurality of the tokens (56/210) record 
"our green and pleasant land" (the original "England's" is used 39 times) (search term: "green and pleasant land" performed on 19 July 2016).

Changing the form of a quotation, whether intentionally or unintentionally, is very common, as several scholars have noted. Regier states:

Every part of a quotation statement is vulnerable to naive, careless, ignorant, malicious, mischievous, prudent, and inventive change. A quoter might disregard some, even most, parts of the statement (Regier 2010: 10).

Knowles (2011: 95) also notes "it is often the case that while particular key words do not change, other elements may vary". Misquoting like this seems to be a ubiquitous feature of quoting. Importantly, these changes can occur even when the author is conscious of using a quotation. Such changes can spread rapidly, especially on the internet, where so much copying and pasting seems to be happening.

Similar to misquoting is attributing a quotation to the wrong source. Scholars have long known that quotations are often wrongly attributed (Knowles 2009: 17-18; Regier 2010: 12-13), and we have already seen two examples of quotations with unclear sources - "There but for the grace of God go I" and "Live to fight another day". The internet especially has allowed for a misattribution to become widespread. There seem to be a few magnets, like Winston Churchill and Mark Twain, who become attached to more quotations than other figures (Knowles 2009: 15; Regier 2010: 13-14).

The discussion so far has focused on changes to the form of the quotation - a quotation may be shortened, adapted, fixed as a template, or inadvertently changed. We have also noted that the attribution can be changed. In addition to these changes, the data from the GloWbE searches reveal that the meaning and reference of the quotations can be changed as well. Quotations can be used with a variety of meanings or applied to a variety of contexts. Over time, quotations often shed details of their original use or acquire new contexts, much like words. In a way, the "meaning" of the quotation changes. Knowles illustrates this with the example of Milton's "chaos and old night" changing from a notion of cosmic disorder to hell or to political disorder (2011: 92-100). Within the GloWbE searches, a good example of meaning extension comes from "tea and sympathy", which can mean sincere concern for others, a useless pretense of concern, a pollyana-ish cheerfulness, an important human touch in institutional situations, and much else. Similarly, we see several examples of reference extension with "yellow brick road". While the core meaning is a clearly-marked road, there are several references that this meaning is applied to. Since the yellow brick road figured in a fantasy novel, the phrase "yellow brick road" is sometimes used to describe metaphorical paths that are more fantastic than practical. Since 
following the yellow brick road was a sure way to arrive at the desired destination of $\mathrm{Oz}$, the phrase "yellow brick road" is sometimes used to emphasize paths leading to goals, like financial security. Since the yellow brick road is easy to see, some hikers use the phrase to refer to easy-to-find trails. In a lot of ways, the changing uses of quotations resemble the semantic change we see with individual words. The applications for "green and pleasant land" range from unabashedly patriotic to ironic to antagonistic sentiments, especially in antiquotes, like "green and prejudiced land", and "green and hateful land". Similarly, "scarlet letter" still refers to public shaming, but the source of shame has generalized to practically any behavior (though the plurality of uses still refer to shame for some sort of sexual behavior).

These changes in form and meaning seem to be a different type of change from the overall change investigated in this paper. Changes in form and meaning are essentially alterations, whereas the overall change - a phrase entering the lexicon is an addition. This leads to an interesting situation in which a change of one type (an addition) apparently depends on changes of a different type (alterations). In this respect, the addition of literary phrases is similar to other types of language change, particularly grammaticalization, lexicalization, and lexical borrowing. In both lexicalization and grammaticalization, phrases can become increasingly analyzed as a single unit, with the phrase taking on grammatical functions in grammticalization (e.g., be going to, be about to) and lexical standing in lexicalization (e.g., mother-in-law, in spite of). Along the way, the phrases may undergo similar changes in form and meaning, such as phonetic reduction, semantic bleaching, and shortening. In the way that a quotation is reduced in form from a direct quotation to an idiom or a term and then takes on a fairly fixed, sometimes non-transparent meaning, this process resembles lexicalization (Brinton \& Traugott 2005: 95-99).

The changes also resemble the naturalization of borrowed words, especially in casual contact situations (Thomason 2001: 72-73). When a word is borrowed, it is often initially marked in writing, whether with italics, foreign diacritics, quotation marks, or explicit glosses (Cannon 1992: 148-149). ${ }^{5}$ With quotations, the use of quotation marks, quotatives, and source attributions all correspond to this stage. For those words that become naturalized, the markers of a foreign word are usually felt to be unneeded, so they gradually drop off. Often the pronunciation will fit the spelling along native phonological patterns, and native processes of inflection, like pluralization, become used. Finally, the word is no longer recognizable as a borrowing, but is instead an unremarkable part of the lexicon (Cannon 1992: 148-149; Winford 2010: 173-175). The progression of a

5 This is only a tendency, of course; Doi (2014: 676) rightly points out that typographic marking is neither criterial nor dispositive. 
quotation from a direct quotation to a fixed phrase or idiom passes through similar stages. Gradually the quotation marks, quotatives, and source attributions fall away. The quotation is worked into prose, rather than featured as a quotation. Sometimes the wording or syntax is made more "natural" or similar to the prevailing patterns (e.g., "grow not old" > "not grow old", "road of yellow brick" $>$ "yellow brick road" $"$ ).

In all these types of language change, we see a combination of additions and alterations. The overall change can be seen as an addition (e.g., a new grammatical structure, a new lexicalized phrase, a new borrowed word), but the process of adding involves alterations. We may well ask how these supporting changes (alterations) relate to the overall change (addition), and whether for literary phrases, at least, the label "change from above" is appropriate for the alterations. Do the shortenings, adaptations, semantic broadening, and other alterations in literary quotations constitute "change from above" as well?

The basic answer will be that they do constitute change from above, as long as we maintain the same kind of analysis for both the overall and the supporting changes. For the overall change of adding a literary phrase to the lexicon, we argued that "change from above" was appropriate, since speakers and writers were conscious of the social valuation of quoting and that the change moved toward a prestigious form of the language. When analyzing alterations, it is not enough to note that speakers and writers are usually conscious of changing quotations, as they shoe-horn them, shorten them, and use them in partly-fixed frames, since the label "change from above" refers to more than just consciousness of the change - it also refers to speakers and writers being conscious of the social valuation of the variants. We therefore need to identify the prestigious variants among these alterations.

For the overall change (addition of phrases to the lexicon), it will be remembered that we defined the prestigious variant as a discursive practice, not necessarily a form, in accord with a provision that Hawkey anticipated (2016: 183). If we keep the practice of quoting as the "prestigious variant" for the changes to a quotation's form, the "change from above" analysis remains the same for both the overall addition and the supporting alterations. The practice of quoting remains prestigious, whether one is using a direct quotation, a partlyfixed frame, an adapted quotation, or a shortened quotation, so long as both the writer/speaker and reader/hearer recognize the phrase as a quotation. Working quotations into one's own prose is still a prestigious discursive practice, especially in registers associated with formal learning, and writers show their

6 In the Project Gutenberg edition of The Wonderful Wizard of Oz (Baum 2008 [1900], the phrase "yellow brick road" never occurs. "Road of yellow brick" occurs twelve times and "road ... paved with yellow bricks" occurs four times. 
cleverness in adapting quotations. Writers and speakers are still choosing the prestigious form (quoting) when they make changes to quotations. If we consider the prestigious variant to be quoting practice and not the original form of the quotation, then a speaker's or writer's use of a quotation - even a misquoted or shortened or otherwise changed quotation - will still constitute the use of the prestigious variant. ${ }^{7}$ When the same prestigious variant is defined for both the overall change (addition to the lexicon) and the supporting changes (alterations in form and meaning), then the two "kinds" of change seem to be the same throughout. Thus the changes occurring during the process of adoption can be analyzed as change from above in the same way that the overall change as an adoption can. Under this analysis, the two types of change (addition and alteration) reflect an issue of granularity. The changes are seen as an addition from a coarse-grained perspective and as alterations from a finer-grained perspective.

The granularity that this analysis provides makes it preferable to what might be an initially more tempting analysis, which is to see the various forms of the quotation as variants of each other and as one of them as the prestigious variant. Because the changes to the quotation's form result in at least two forms (the original form like "a plague" and the altered form like "a pox"), these changes look more like linguistic variables in variationist studies in that they consist of multiple forms performing one function. So we might be tempted to look for the prestigious variant as a form, instead of as a discursive practice. Perhaps the direct quotation, for example, would be considered the most prestigious form, since in academic writing, at least, quotations most closely connected to their source carry the most prestige, and accurate attribution and replication are required. Even when writers consciously shoe-horn a quotation into their prose, they are expected to respect the integrity of the quotation by making their changes clear with quotation marks, square brackets, skillful phrasing and the like. From this point of view, when writers change the wording of quotations or shorten them or vary parts of them in partly-fixed frames or efface their context or expand their application or attribute them to the wrong author, the writers would be changing the quotation away from the most prestigious form.

But analyzing particular forms of the quotation as more or less prestigious than other forms presents some problems. First, it is not clear that speakers and writers are aware of different social evaluations of shortened or adapted forms versus the original form. The much more important consideration for prestige is

$7 \quad$ Even when the literary origin of the quotation is effaced, it may still retain connections to the registers with high prestige where it was originally used, so that speakers unaware of the phrase's literary origins may still be conscious of the prestige of the registers most associated with the phrase. 
the quoting practice itself. When writers use a partially fixed phrase, like "to code or not to code, that is the question", the fact that they are quoting is more important for establishing prestige than that they have changed the quotation. In fact, the partly-fixed frame may be a better structure than the direct quotation for a writer in a given situation. That writers have different uses for different versions of the quotation points to a serious problem in trying to identify one of the forms as more prestigious: the different versions are more likely functional variants than social variants. Direct quotations are more prestigious only when direct quotations are called for. When adaptations or shortened forms are called for, a shortened or shoe-horned version is a better choice. These variants perform different functions, so they cannot index social value very well. For that reason, an analysis of the different forms as variants of each other is not as useful for determining whether they are changes from above.

We are still left with those practices that seem to be clearer departures from the prestigious forms. The first is misquoting. If shortening and adapting are not really variants of a direct quotation, at least a misquoted passage would be a variant of an accurately quoted one. "A pox on both your houses" would seem to be functionally equivalent to "A plague a' both houses", and since it alters the original, it could be seen as less prestigious. In this sense, it could be argued that misquoting does not move toward the prestigious form and therefore is not change from above. That would be a fair consideration. Writers are not conscious that they are changing the quotation or that the original quotation carries more prestige. But again, the notion of granularity comes into play. If the language change to be explained is limited to the alterations in the form of a quotation, misquoting could be seen as more closely resembling "change from below". But if the language change to be explained is the overall process of adding a literary quotation to the language, the change remains a change from above and is not affected by misquoting. That is because the prestigious practice of quoting will still be recognized, even if the form of the quotation is changed. Furthermore, misquoting is not crucial to the adoption of a literary phrase in the same way that shortening, adapting, and contextual bleaching are.

One final change raises questions about change from above: the change from being aware to being unaware of a phrase's literary origin. If the prestigious variant is defined as the quoting practice itself, then we cannot speak of speakers and writers selecting the prestigious variant when they no longer recognize the phrase as a quotation. At such a point, speakers and writers are not even aware of the social value of using the phrase, and in fact, the phrase may be devalued as a cliché. Is this stage still included in "change from above"?

That depends on how much of a change has to remain above consciousness. Arguably, speakers and writers do not have to remain consciously aware of the social value of the prestigious variant as the variant loses its indexing quality. If 
the prestigious variant approaches categorical use and supplants all other variants, the variant will be less marked. At some point speakers may become unaware that it ever indexed anything. The widespread use of the variant is the key. As a literary phrase becomes increasingly used in more and more contexts and registers, it will gradually shed the identification with the original quotation. The increasing use wears down the indexing or marked character of the construction, and speakers and writers become unaware of any special advantage of these particular phrases. As Knowles (2009: 15) states,

once a particular quotation has lodged itself in the public consciousness, it is as subject to the process of language change as any other vocabulary item, and it is as likely to be used without the user necessarily realizing that they are quoting from a particular source.

Many of the phrases from Shakespeare, like rhyme and reason noted earlier, seem to have lost most, if not all of their literary origin. In that respect, they may be regarded as more deeply-incorporated into the language and resemble a linguistic variant that has become categorical. That is why writers like Bragg can celebrate Shakespeare's contribution to the language: on some level, the additions have become so successful that they no longer feel like quotations. The social evaluation of the phrases move from above consciousness to below it, and that change should be seen as the culmination of a change from above, not a contradiction to it.

On the other hand, if a change from above does not become categorical, but reaches stable variation, the distribution of the originally prestigious variant may continue behaving like a change from above for a long time, as Alexandra D'Arcy and Sali Tagliamonte (2011) have shown in their examination of the relative pronoun who, when used with human antecedents and in subject position of restrictive clauses. They found evidence that in speech, who, which shows many indications of having been introduced and diffused as a prestigious variant from above, continues to index such social categories as education and employment. The first instance of who in the historical record, write D'Arcy and Tagliamonte, dates from 1426 - 138 years before Shakespeare's birth - and yet it is still indexing prestige. Apparently the effects of change from above can be longlasting.

From the corpus data on literary quotations, it appears that the status of literary quoting may remain long-lasting, as well. The kind of loss of context that makes "budge an inch" into a fixed-phrase instead of a quotation is relatively rare. In most cases, the connection to the practice of quoting remains, even if the connection to the particular origin wears away. It would be difficult to say that any of the 500-plus quotations examined for this study have reached such fullyincorporated status as "thin air" - "tea and sympathy" might be the closest. And 
even among the numerous quotations from Shakespeare and the King James Bible that have achieved widespread currency, most very likely are still widely recognized as literary quotations, like "sweets to the sweet", "winter of our discontent", "brother's keeper", and "let there be light". Perhaps the durability of literary quotations as a prestigious discursive practice is one more way that the addition of literary quotations resembles change from above.

In conclusion, the addition of quotations to the lexicon, besides providing a point of interest in popularized histories of the language, provides an interesting focus for exploring the notion of change from above. It would seem that we need a term like "change from above" for a phenomenon that involves such a high degree of consciousness, and even though the term was coined for variationist approaches to language change, perhaps it can still be useful for describing the addition of elements to the lexicon. In variationist studies, the element that must remain above speakers' and writers' consciousness is the social valuation of linguistic variables; for literary quoting, the social valuation of the quoting practice is what remains above consciousness. The addition of a phrase to the language itself involves several alterations to the quotation's form and meaning, and these alterations can still be analyzed as part of the quoting practice. Importantly, speakers and writers do not set out to add phrases to the lexicon or change the form or meaning of quotations, even when they are conscious of using quotations or changing their form. Instead speakers and writers use literary quotations to achieve their own ends for speaking and writing. As often noted, yet as easily forgotten, change needs no special motivation. Change from above is not necessarily separate from 'invisible hand processes' even if it involves consciousness.

\section{REFERENCES}

Baum, L. Frank 2008 [1900]. The Wonderful Wizard of Oz. Project Gutenberg. http://www.gutenberg.org/files/55/55-h/55-h.htm. (accessed on 18 February 2019)

Bent, S. A. 1887. Familiar short sayings of great men (6th edn). Boston, MA: Ticknor \& Co.

Bénéjam, Valérie. 2005. Passports, ports, and portraits: Joyce's harbouring of Irish identity. Genetic Joyce Studies 5.2.

https://www.geneticjoycestudies.org/GJS5/GJS5Benejam.htm. (accessed on 7 April 2018).

Boorstin, Daniel J. n.d. The Americans: The democratic experience. https://homepage.eircom.net/ odyssey/Quotes/History/Boorstin_Americans_3.html. (accessed on 9 April 2018)

Bragg, Melvyn. 2003. The adventure of English: The biography of a language. New York, NY: Arcade. 
Brinton, Laurel \& Elizabeth Closs Traugott. 2005. Lexicalization and grammaticalization in language change. Cambridge: Cambridge University Press. DOI: 10.1017/CBO9780511615962

Cambridge Advanced Learner's Dictionary and Thesaurus. 2016. https://dictionary.cambridge.org/us/dictionary/english/. (accessed on 9 April 2016)

Cannon, Garland. 1992. Malay(sian) borrowings in English. American Speech 67(2). 134-162. DOI: $10.2307 / 455451$

Crystal, David. 2004. The stories of English. Woodstock, NY: Overland Press.

D'Arcy, Alexandra \& Sali A. Tagliamonte. 2010. Prestige, accommodation, and the legacy of relative who. Language in Society 39(3). 383-410. DOI: 10.1017/S0047404510000205

D'Arcy, Alexandra \& Sali A. Tagliamonte. 2015. Not always variable: Probing the vernacular grammar. Language Variation and Change 27(3). 255-285. DOI: 10.1017/S0954394515000101

Davies, Mark (ed.). 2013. Corpus of Global Web-Based English: 1.9 billion words from speakers in 20 countries. https://corpus.byu.edu/glowbe/.

De Breadun, Deaglan. 2012. A sense of coming together as many turn out to greet 'Banríon Eilís a Dó”" Irish Times (27 June 2012). https://www.irishtimes.com/news/a-sense-ofcoming-together-as-many-turn-out-to-greet-banr\%C3\%ADon-eil\%C3\%ADs-ad\%C3\%B3-1.1069003. Accessed April 23, 2018.

De Cock, Sylvie, Sylviane Granger, Geoffey Leech \& Tony McEnery. 1998. An automated approach to the phrasicon of EFL learners. In Sylviane Granger (ed.), Learner English on computer, 67-79. London: Longman.

Doi, Schun. 2014. The naturalisation process of the Japanese loanwords found in the Oxford English Dictionary. English Studies 95(6). 674-699. DOI: 10.1080/0013838X.2014.942100

Durkin, Philip. 2012. Variation in the lexicon: The 'Cinderella' of sociolinguistics?: Why does variation in word forms and word meanings present such challenges for empirical research? English Today 28(4). 3-9. DOI: 10.1017/S0266078412000375

Fillmore, Charles J. 1978. On the organization of semantic information in the lexicon. In Donka Farkas, Wesley M. Jacobsen \& Karol W. Todrys (eds.), Papers from the Parasession on the Lexicon, Chicago Linguistic Society, April 14-15, 1978, 148-173. Chicago, IL: The Society.

Finnegan, Ruth. 2011. Why do we quote? The culture and history of quotation. Cambridge: Open Book Publishers. DOI: 10.11647/OBP.0012

Goldsmith, Oliver. 1761. The art of poetry on a new plan, illustrated with a great variety of examples (vol. 2). London: Newbery.

Grieve, Jack, Andrea Nini \& Diansheng Guo. 2017. Analyzing lexical emergence in Modern American English online. English Language and Linguistics 21(1). 99-127. DOI: $10.1017 /$ S1360674316000113

Hawkey, James. 2016. Developing discussion of language change into a three-dimensional model of linguistic phenomena. Language and Linguistics Compass 10(4). 176-190. DOI: 10.1111/lnc3.12180

Huise, John. 1633. Florilegium Phrasicon, Or a Survey of the Latine Tongue, According the Elegancy of its Proper Dialect Necessary for all Young Students in the same for their better Imitation, and Practice Thereof, Either by their Voice, or Pen. n.p.: A. M 
Jajah, Mahmoud. 2012. Everyday motivational quotes. Thoughts of a Zongo Boy! https://mahmoudjajah.com/2012/03/27/everyday-motivational-quotes/. (accessed on 9 April 2018)

Joyce, James. 1961 [1922]. Ulysses. New York, NY: Vintage.

Knowles, Elizabeth. 2009. Borrowed words: Using the words of others to express what we want to say. In R. W. McConchie, Alpo Honkapohja \& Jukka Tyrkkö (eds), Selected proceedings of the 2008 Symposium on New Approaches in English Historical Lexis (HEL-LEX 2), 14-22. Somerville, MA: Cascadilla Proceedings Project.

Knowles, Elizabeth. 2011. Chaos and old night: A case study in quotation usage. In Olga Timofeeva \& Tanja Säily (eds.). Words in dictionaries and history: Essays in honour of R. W. McConchie, 91-108. Amsterdam: John Benjamins. DOI: 10.1075/tlrp.14.09kno

Labov, William. 1972. Sociolinguistic patterns. Philadelphia, PA: University of Pennsylvania Press.

Marmur, Michael. 2014. Why Jews quote. Oral Tradition 29(1). 5-46.

McCrum, Robert, William Cran \& Robert MacNeil. 1986. The story of English. New York, NY: Penguin.

Michael, Lev. 2015. Social dimensions of language change. In Claire Bowern \& Bethwyn Evans (eds), The Routledge handbook of historical linguistics, 484-502. London: Routledge. DOI: $10.4324 / 9781315794013 . c h 22$

Newman, John Henry. 1976 [1858]. The idea of a university. Oxford: Clarendon Press.

nicolemm. 2014. Profile. Daily Kos. https://www.dailykos.com/blog/nicolemm. (accessed on 23 April 2016).

O'Toole, Garson. 2014. There but for the grace of God go I. Quote Investigator. https://quoteinvestigator.com/2014/07/06/grace/. (accessed on 23 April 2018).

Romaine, Suzanne. 2003. Variation in language and gender. In Janet Holmes \& Miriam Meyerhoff (eds.), The handbook of language and gender. Oxford: Blackwell. DOI: 10.1002/9780470756942.ch4

Regier, Willis Goth. 2010. Quotology. Lincoln, NE: University of Nebraska Press.

The Riverside Shakespeare. 1974. Atlanta, GA: Houghton Mifflin.

Robinson, Justyna. 2012. A gay paper: Why should sociolinguistics bother with semantics?: Can sociolinguistic methods shed light on semantic variation and change in reference to the adjective gay? English Today 28(4). 38-54. DOI: 10.1017/S0266078412000399

Surwillo, James. 2017. Metamodern leadership: A History of the seven values that will change the world. New York, NY: Page Publishing.

Tagliamonte, Sali A. 2011. Variationist sociolinguistics: Change, observation, interpretation. Chichester: Wiley-Blackwell.

Thomason, Sarah G. 2001. Language contact: An introduction. Washington, DC: Georgetown University Press.

Winford, Donald. 2010. Contact and borrowing. In Raymond Hickey (ed.), Handbook of language contact, 170-187. Oxford: Wiley-Blackwell. 10.1002/9781444318159.ch8

Wray, Alison. 2008. Formulaic language: Pushing the boundaries. Oxford: Oxford University Press.

Wolfram, Walt \& Natalie Schilling-Estes. 2005. American English: Dialects and variation (2nd edn). Oxford: Blackwell. 